\title{
Theodoros Terzopoulos'un Dionizyak Oyuncusu ve Sahnedeki Mevcudiyeti
}

\section{Theodoros Terzopoulos'Dionysiac Actor and Her/His Presence on the Stage}

\author{
Burcu Halaçoğlu ${ }^{1}$
}

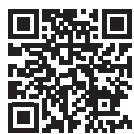

*Bu makale 2019 yılında İstanbul Üniversitesi Sosyal Bilimler Enstitüsü Tiyatro Eleştirmenliği ve Dramaturji Anabilim Dalı́nda tamamladığım "Çağdaş Oyunculuk Eğitiminde "Mevcudiyet" Kavramı ve Bir Uygulama" başlıklı doktora tezinden hareketle hazırlanmıștır.

'Dr. Araştırma Görevlisi, İstanbul Bilgi Üniversitesi Illetişim Fakültesi Sahne ve Gösteri Sanatları Yönetimi, İstanbul, Türkiye

\section{ORCID: B.H. 0000-0001-6259-2273}

Sorumlu yazar/Corresponding author: Burcu Halaçoğlu,

IIIstanbul Bilgi Üniversitesi, İletişim Fakültesi, Sahne ve Gösteri Sanatları Yönetimi, Istanbul, Türkiye

E-posta/E-mail: burcu.halacoglu@bilgi.edu.tr

Başvuru/Submitted: 24.01.2020

Revizyon Talebi/Revision Requested:

12.04.2020

Son Revizyon/Last Revision Received:

21.04.2020

Kabul/Accepted: 24.04 .2020

\section{Atıf/Citation:}

Halacoglu, Burcu. "Theodoros Terzopoulos'un Dionizyak Oyuncusu ve Sahnedeki Mevcudiyeti" Tiyatro Eleştirmenliği ve Dramaturii Bölümü Dergisi 30, (2020): 53-69

https://doi.org/10.26650/jtcd.679357

\section{ÖZ}

Theodoros Terzopoulos tiyatrosunun odağına oyuncuyu koyar ve kendi tiyatro dilini yıllar içinde geliştirdiği oyunculuk eğitim ve araştırması üzerine kurar. Bu eğitim ve araştırma sürecinin bir ürünü olarak ortaya çıkan oyunculuk tekniğinin ana malzemesi oyuncunun bedenidir. Oyuncunun bedeninin sahip olduğu potansiyeli ortaya çıkarmak için öncelikli hedef ise tıkalı durumdaki enerjileri serbest bırakmaktır. Böylece oyuncu, özgür bir enerji kanalına dönüşen bedeni aracılığıyla bir varoluşun, bir esrime halinin peşine düşer. Esrime halinde zihin ve beden ayrımı tümüyle yok olur; oyuncu bütün bedeniyle hissettiği bir mevcudiyeti deneyimler. Bu çalışmada Terzopoulos'un oyunculuk araştırmalarında hedeflediği dionizyak esrime halinin oyuncunun mevcudiyeti ile ilişkisi üzerinde durulmuş, bu ilişkinin oyuncunun sahne üzerindeki mevcudiyetine nasıl bir katkı sunabileceği araştırılmıştır.

Anahtar Kelimeler: Tiyatro, Oyunculuk, Oyunculuk Tekniği, Oyuncunun Mevcudiyeti, Theodoros Terzopoulos

\section{ABSTRACT}

Theodoros Terzopoulos places the actor at the center of his theater and builds his own theater language on actor training and research he developed over the years. The main material of his acting technique, which is a product of this training and research process, is actor's body. In order to reveal the potential of the actor's body, the primary objective is to release the energies that are blocked. Thus, the actor pursues a state of being, an ecstasis through his body which becomes a free energy channel. In the state of ecstasis, the distinction between mind and body disappears completely; the actor experiences a presence in which he involves with his whole body. This study analyzes the relationship between the presence of the actor and the state of dionysiac ecstasis aimed at by Terzopoulos and examines the ways this relationship can contribute to the presence of the actor on the stage.

Keywords: Theater, Acting, Acting Techniques, The Presence of the Actor, Theodoros Terzopoulos 


\section{EXTENDED ABSTRACT}

This study analyzes the relationship between the presence of the actor and the state of dionysiac ecstasis aimed at by Theodoros Terzopoulos and also examines the ways this relationship can contribute to the presence of the actor on the stage. In order to relate the presence of the actor with the state of dionysiac ecstasis, firstly theater of Terzopoulos is shortly described and what is the main focus of him is defined. Then the relationship between the presence of the actor and the state of dionysiac ecstasis is examined. The main material of Terzopoulos' technique is the actor's body and the most distinctive quality of his theater is the actors' use of body. While working on the actor's body his primary aim is to release the energies that are blocked. Only then, the actor can reach the point of ecstasis.

The word "ecstasis" (ékstasis) was used in the meaning of "changing place or state, losing consciousness and forgetting oneself" in Ancient Greek. In Latin it has the same roots as the verb "exsistere", which is used to mean "exist and occur" and is used in the same sense as the word "vecd" in Arabic which has the same root of the word "presence". Based on all these words, it can be said that the state of ecstasis is related to going beyond the daily presence and experiencing a more deeply felt wholeness. Terzopoulos emphasizes that this deep experience is actually an ongoing change of state and presence and finds the roots of this transcendental state in tragedies and the Dionysian mystery. After long trials Terzopoulos formulates a method of reaching this ecstatic state which is totaly physical. He technically summarizes this method as following: "It is about releasing seven critical points in the spine so that energy is not blocked vertically. Energy should flow in the vertical plane without any obstacles. This is the first job in our theater. When energy flows vertically, it moves both upwards, to the sky and to the earth at the same time. Thus, it spreads in all directions and becomes universal. You turn into Dionysus." 2

Terzopoulos' expressions about energy remind Eugenio Barba's work on energy. The presence of the actor is precisely related to this energy, it is this energy that gives the actor's body vitality and enables it to be present. Although this energy is a "intangible, unidentifiable and immeasurable force", , the word of presence must be understood literally as "the ability to be and feel alive and to convey this awareness to the audience." ${ }^{4}$ Working on the body parts in depth he tries to reach a flow of energy where every part of the body can be the center.

1 Sevan Nişanyan, Sözlerin Soy Ăgacı: Çağdaş Türkçe’nin Etimolojik Sözlü̆ğ̈̈, (İstanbul: Adam Yayınc1lık, 2003), 136-139.

2 Frank M. Raddatz, "The Metaphysiscs of the Body- Theodoros Terzopoulos in Conversation with Frank M. Raddatz". Reise mit Dionysos. Das Theater des Theodoros Terzopoulos: Journey with Dionysos. The Theatre of Theodoros Terzopoulos, Ed. Frank M Raddatz,.(Berlin:Berlin:Theater der Zeit, 2006), 165.

3 Eugenio Barba ve Nicola Savarese, Oyuncunun Gizli Sanatı: Tiyatro Antropolojisi Sözlüğü, çev. Ayşın Candan, Tarhan Onur, Aslı Seven, (İstanbul: İstanbul Bilgi Üniversitesi Yayınları, 2017), 165.

4 a.e., 266. 
These centers can also change constantly. It is the state of being and experience itself at that moment rather than showing or acting something. Terzopoulos mentions that he aims at the presence of the actor with this; his purpose is "ontologically pre-theater" beyond anything like character, role and psychology.

Terzopoulos's acting technique provides a framework that can be used to improve the actor's presence on stage. The actor's relationship with the play develops thanks to the physical exercises applied for the development of the actor's holistic body perception and the circulation of vital energy, especially through the detailed work and activation of the seven parts. In this sense, all physical works, breathing and concentration exercises that enable both the energy centers in the body to relax and become active, provide an integrated workspace that every actor can apply to improve the presence of stage, even if she/he is not an actor of his theater. It also gives a structural suggestion to work on the presence as a wholistic training. 
Theodoros Terzopoulos kurucusu ve yönetmeni olduğu Attis Tiyatrosu'nda yıllarca üzerine çalıştığı ve geliştirdiği, kendine özgü bir oyunculuk anlayışının ve biçiminin peşine düşmüştür. Kendisinin ifadesi ile 21. yüzyıl tiyatrosu başka bir yöne evrilmelidir ve oyuncunun sanatı aracılığıyla yeniden düşünülmelidir. ${ }^{5}$ Terzopoulos, tiyatrosunun odağına oyuncunun sanatını koyar ve yönettiği oyunlarda kendi oyunculuk eğitim ve araştırmasının doğrudan görünür olduğu örneklerini sunar. Düzenlediği atölyelerde de aynı araştırmayı ve eğitimi Attis Tiyatrosu dışındaki oyuncularla da paylaşma firsatı bulur. Bu araştırmalarında ana malzemesi oyuncunun bedenidir. Terzopoulos'un tiyatrosunda oyuncu, bedeni ile bir varoluşun, bir esrime halinin aracısı olur. Bu çalışmada Terzopoulos'un oyunculuk araştırmalarında hedeflediği dionizyak esrime halinin oyuncunun mevcudiyeti ile ilişkisi üzerinde durulmuş, bu ilişkinin oyuncunun sahne üzerindeki mevcudiyetini nasıl geliştirdiği araştırılmıştır.

Terzopoulos oyuncu ile çalışmasının odağına oyuncunun bedeni yerleştirir. Günümüz tiyatrosunun gelişimine katkıda bulunmak isteyen bir oyuncu "gerek yaşadığı hayatın gerekse sanatının temel ilkelerini yeniden tanımlamak zorundadır. Bunu yaparken, oyuncunun temel malzemesi Bedendir." ${ }^{\circ}$ Marrianne MacDonald da benzer şekilde Terzopoulos'un tiyatrosunun en ayırt edici özelliğinin oyuncuların bedenlerini kullanış biçimi olduğunu söyler. Beden üzerine kurulu bir oyunculuk araştırması, özellikle Terzopoulos'un ulaşmayı hedeflediği oyuncu bedeni düşünüldüğünde, uzun süren bir çalışma sürecini gerektirir. ${ }^{7}$ Kendisi bu eğitim sürecini Dionysos'un Dönüşü adlı kitabında ayrıntılarıyla anlatır. Eğitimin öncelikli amacı kendi ifadesiyle "açık kanallara sahip, açık bir evren haline gelene dek bedeni işlemektir." Oyuncular bu işleme sürecinde, "soluk", "enerji”, "ritim”, "konuşma”, "his" ve "zaman” gibi öğelerle ilişkili olarak bedenleri üzerine derin bir araştırmaya girer.

Terzopoulos araştırma aşamasından performansa kadar süren bu yaratıcı süreçte öncelikli görevin tıkalı durumdaki enerjileri serbest bırakmak olduğundan söz eder ve ekler:

“Oyuncunun günlük alıştırmalarının uygulama alanındaki hedefi, hayal gücünü itiraz kabul etmeyen teknik kurallardan ibaret kapalı bir sistem içine hapseden çabuk sonuçlar almak değildir. Egzersizler, farkındalık işlevlerini harekete geçirir ve Enerjik Beden 'i şekillendirir."”

Terzopoulos'a göre bütün bedenler aynı şekilde tepki verir. Bütün bedenlerin temel ihtiyaçları aynıdır. Beden kendisini hep aynı şekilde organize eder. "Yunan, Alman ya da Japon bedeni diye

\footnotetext{
Theodoros Terzopoulos, Dionysos 'un Dönüşü, çev. Burç İdem Dinçel, (İstanbul: Habitus Kitap, 2016), 13. a.e., 10 .

Marianne McDonald, "Theodoros Terzopoulos, A Director For the Ages: Theatre of the Body, Mind, and Memory", Reise mit Dionysos. Das Theater des Theodoros Terzopoulos: Journey with Dionysos. The Theatre of Theodoros Terzopoulos, Ed. Frank M Raddatz, (Berlin:Theater der Zeit, 2006), 8.

8 Terzopoulos, Dionysos'un Dönüşü, 70.
}

9 a.e., 16 
bir şey yoktur. Beden, pek çok kökü olan bir ağaç gibi evrenseldir." "Grotowski'nin görüşlerini de yankılar şekilde, oyuncu bu evrensel bedene sosyal bir varlık olmanın gerekliliği ile edindiği yapay maskelerden kurtularak ulaşabilir. Bu maskelerden kurtulmak için ise gündelik enerjinin tükenmesi gerekir. Çok uzun saatler süren fiziksel çalışmalar bedeni tükenme noktasına getirir. Oyuncu ancak bu noktadan sonra araştırılan esrime noktasına ulaşılabilir.

Terzopoulos esrimenin fiziksel olasılıklarını araştırmaya Euripides'in Bakkhalar oyununu sahnelemeye çalışırken başlar. Ona bu konuda ilham veren şey, 17.yüzyıla ait bir kitapta karşısına çıkan, tanrı Asclepious için inşa edilmiş bir hastanede, ritüel olarak uygulanan bir tedavi yöntemi olacaktır. Gün doğuşuyla başlayan ve sekiz saat aralıksız devam eden " $b u$ egzersiz, katılımcılarda Afrika danslarında gözlemlenene benzer bir enerji açı̆̆a çıkarır ve kiminin midesinde, kiminin kalbinde hissettikleri acıları kaybolur." "11 McDonald bu anlar1 "insanın özünden gelen aydınlanmanın ışı̆̆ının yayıldı̆̆ı" anlar olarak betimler. "Burası insanın nihayet görebildiği ve hissetmenin bütün bedenle deneyimlendiği yerdir.” Oyuncu bu gördüğ̈̈ hakikati, sonrasında seyircisiyle paylaşacaktır. ${ }^{12}$

Esrime kelimesi, yani “ekstaz” (ékstasis) Eski Yunanca'da “yer veya durum değiştirmek, bilincini yitirmek ve kendinden geçmek" anlamında kullanılır. Ekstaz Latince "var olmak ve zuhur etmek" anlamında kullanılan "exsistere" fiili ile aynı köklere sahiptir"13 ve Arapça mevcudiyet kelimesinin kökeninde bulunan "vecd" kelimesi ile aynı anlamda kullanılır. İlişkili olduğu bütün bu kelimelerden de yola çıkarak, esrime halinin bu anlamıyla gündelik olanın ötesine geçme ve daha derinlemesine hissedilen bir varoluşu deneyimleme ile ilişkili olduğu söylenebilir. Terzopoulos bu derin deneyimin aslında sürekli devam eden bir oluş ve hal değişikliği olduğunu vurgular: "Oyuncunun iç ve diş uyaranlara açık, sürekli bir değişim halinde olan bedeni, yaşam ve ölüm arasindaki ipin üstünde dengede durur”. Terzopoulos bu aşkın halin kökenlerini tragedyalarda ve Dionizyak esrimede bulur. Dionysos oyuncuya bu açıdan bereketli bir araştırma alanı sunmuştur:

"Oyuncuyu, yapısının derinliklerinde gizli, zihin tarafindan baskılanmıs ve bastırılmış ilkel bedenini aramaya çă̆ırır. Emsalsiz psikofiziksel enerji kaynaklarına ve fiziksel bedenin limitlerinin fersah fersah ötesinde sinirlara sahip bu Beden oyuncunun temel malzemesidir. Ve yapının derinliklerine gömülü hatıralar tarafindan sürekli yenilenir."'14

10 Frank M. Raddatz, "The Metaphysiscs of the Body- Theodoros Terzopoulos in Conversation with Frank M. Raddatz". Reise mit Dionysos. Das Theater des Theodoros Terzopoulos: Journey with Dionysos. The Theatre of Theodoros Terzopoulos, Ed. Frank M Raddatz, 136-175, (Berlin:Theater der Zeit, 2006), 160.

11 Marianne McDonald, Ancient Sun Modern Light, (Columbia University Press, New York:1992), 164 ve Theodoros Terzopoulos, "Historical Review and Methodology", Theodoros Terzopoulos and The Attis Theatre (History, Methodology and Comments),İ (Agra Publications, Athens, 2000), 76, Alıntılayan: Karaboğa, Tragedya ile Sinırları Aşmak, (İstanbul: E Yayınları, 2008), 51.

12 Mcdonald, Reise mit Dionysos. Das Theater des Theodoros Terzopoulos: Journey with Dionysos. The Theatre of Theodoros Terzopoulos, 9.

13 Sevan Nişanyan, Sözlerin Soy A ğacı: Çăgdaş Türkçe’nin Etimolojik Sözlüğü, 136-139.

14 Terzopoulos, Dionysos 'un Dönüşü, 15. 
Buradan yola çıkarak, esrime yolu ile beden hafızasına gömülü ilksel hatıraların kışkırtıldığından söz edebiliriz. Aynı zamanda bu araç, oyuncunun "hissiyatını, içgüdülerini, hayal gücünü ve Öz Fikri'ni” kendi içinde geliştirmesi için de zengin içsel malzemeler sunar. Terzopoulos'a göre oyuncu böylece "kendi bedeni hakkında çarpık bir imge sunan narsisizme direnir" hale gelir. Fiziksel yorgunluğun sınırlarını aşarak kendi psikolojik ve fiziksel zayıflıklarını geliştirir. En önemlilerinden biri de esrime anında oyuncu kendiliğindenliği doğrudan deneyimler ki Terzopoulos'a göre kendiliğindenlik “içsel ve dışsal uyaranlara karşı bir tepki gösterme yeteneğ $i$ " dir. Esrime anındaki kendiliğindenlik sayesinde, oyuncunun günlük yaşamın dayattığı sayısız korku ve kısıtlamalardan "kendini arındırma"sı kolaylaşır. ${ }^{15}$

Terzopoulos esrimeye her şeyden önce fiziksel açıdan yaklaşır. Bedenleri esrime anına taşıyacak bir teknik araştırmasına düşer ve bu konuda iki yönelim belirler. Karaboğa bu yönelimleri şöyle ifade eder:

"Birincisi, bedensel sınırların aşılması için acının üzerine gidilmesi, fiziksel yorgunluk ve acının belirginleştiği aşamada durmaksızın ilerlenmesi esastır. Bedenin durmak istediği yer aslında bilinçli kontrolün de sınır noktasıdır ama ondan sonrasında yeni, beklenmedik ve çok boyutlu yaşamsal kaynakla yüzleşme imkanı doğar. İkincisi, bedendeki değişim dışarıdan bir uyarıcı yoluyla değil, kan dolaşımının hızlandırılması, nefes alışverişinin gündelik tartımın dışına çıkılarak dengesizleştirilmesi, bedende yeni enerji kanallarının açılması ve bedenin kendisini her aşamada yeni koşullara uyarlaması sayesinde gerçekleşir."16

$\mathrm{Bu}$ yönelimlerden yola çıkarak Terzopoulos pek çok fiziksel egzersiz üzerine çalışır. Karaboğa süreç içerisinde bu egzersizlerin rafine edildiğinden, elde edilen sonuçlara göre değiştirildiğinden ve sonunda bugün hala geçerliliğini koruyan bir formülasyona ulaşıldığından bahseder. ${ }^{17}$ Terzopoulos uzun denemeler sonunda erişilen bu esrime yöntemini teknik olarak şöyle özetler:

"Omurgadaki yedi kritik noktanın serbest bırakılmastyla ilgilidir, böylece enerji dikey olarak engellenmemiş olur. Enerji dikey düzlemde hiçbir engele takılmadan akabilmelidir. Tiyatromuzda ilk iş budur. Enerji dikey açıdan aktığında, aynı anda hem yukarıya yani göğe, hem de yeryüzüne doğru hareket eder. Böylece bütün yönlere yayılmış olur ve evrenselleşir. Dionysos'a dönüşürsünüz. "'18

Terzopoulos'un enerji ile ilgili ifadeleri, Eugenio Barba'nın enerji üzerine çalışmalarını hatırlatır. Uzakdoğu tiyatrosu üzerine araştırmalar yapan Barba da enerjiye yönelir ancak Barba’ya göre bu kelime pek çok yanlış anlaşılmaya açıktır.

15 a.e., 15

16 Karaboğa, Tragedya ile Sinırları Aşmak, 76-77.

17 a.e., 77.

18 Raddatz, Reise mit Dionysos. Das Theater des Theodoros Terzopoulos: Journey with Dionysos. The Theatre of Theodoros Terzopoulos, 165. 


\begin{abstract}
"Enerji kavramı hem apaçık hem de güç bir kavramdır. Onu daha çok dış itkilerle, kas ve sinirsel etkinlik fazlasiyla ilintilendiririz. Ancak enerji, ayn zamanda yakınlık içeren, hareketsiz ve sessizlik ortamında nabız atışları duyulan, uzamda dağılmaksızın zaman içinde akan çekinik bir güçtür. Enerji çoğu kez baskıcı ve şiddet içeren davranış örneklerine indirgenir. Ama aslında oyuncunun belirleyebildiği, uyandırıp biçimlendirebildiği kişisel bir ısı yoğunluğudur. Her şeyden önce araştırılıp keşfedilmesi gerekir."19
\end{abstract}

Oyuncunun mevcudiyeti tam da bu enerjiyle alakalıdır, ona canlılık veren, varlık göstermesini sağlayan bu enerjidir. Bu enerji her ne kadar "elle tutulamaz, tanımlanamaz ve ölçülemez bir güç "20 olsa da mevcudiyet sözü kelime anlamında anlaşılmalıdır, "olmak ve canlı hissetmek ve bu farkındalı̆̆ izleyicilere aktarma yetisi olarak." ${ }^{21}$ Barba enerjiyi en basit haliyle "çalışır olmak, iş başında olmak" olarak tanımlar ve oyuncunun bedeni anlatım öncesi (pre-expressive) bir düzeyde bu çalışır olma halini tutuyor olmalıdır. ${ }^{22} \mathrm{Bu}$ da oyuncunun mevcudiyetinin, Barba'nın deyimiyle sahne biosunun ön koşuludur. Bu enerji, günlük ve kültürel alışkanlıklar zihninden ve bedensel repertuardan tümüyle silindiğinde açığa çıkar. ${ }^{23}$ Daha önce sözünü edildiği gibi Terzopoulos da benzer şekilde düşünür: oyuncunun enerjisi ancak tıkalı olanın serbest bırakılması ile açığa çıkar, kendini gösterir. Terzopoulos enerjiyi şöyle tanımlar:
"Modern fizikte enerji, bedenin dahili kapasitesine tekabül eden bir devinim birimidir. Dolayısiyla enerji, bedenin zaman ve mekan içerisindeki daimi değiş̧imine denk bir devinim olmakla birlikte aynı zamanda içsel (duygusal) bir devinimdir. Enerji, bir komut misali oyuncuya dışarıdan aşılanan soyut bir fikir olmaktan ziyade, bir deneyim ve fiziksel hafiza şeklinde algılanir." ${ }^{24}$

Bu anlamda Terzopoulos şu soruyu yöneltir, oyuncunun bedeni bu enerjinin taşıyıcısı haline nasıl gelecektir? Öncelikle bedenin bütünlük ve bir aradalık algısını geliştirmek için onu parçalara ayırmak ve her parçayı ayrıntılı olarak çalışmak gerekir. Bu amaçtan yola çıkarak bedeni yedi enerji bölgesine böler. Terzopoulos'un enerji bölgeleri fikri yoga ve savaş sanatlarındaki çakra ve enerji bölgeleriyle örtüşse de çıkış noktası itibariyle farklıdır ve kendisinin ifadesiyle kaynağını "bedenin Dionizyak malzeme içerisindeki davranışlarının incelemesinden alır."25 Bu davranışlar Karaboğa'ya göre bir tür hatırlamadır:"Apollon ve Dionysos ’un başlangıçta ve bir zamanlar aynı bedende olduğunun hatırlanmasıdır. ${ }^{26}$ Apollon sağduyuyu, aklı ve 1şı̆̆ temsil ederken karşısındaki Dionysos coşkunun, özgürlüğün, taşkınlığın ve karanlığın tanrısıdır. Terzopoulos bu anlamda hem Apollon hem de Dionysos’u aynı bedende taşımaktan söz eder:

19 Barba ve Savarese, Oyuncunun Gizli Sanatı: Tiyatro Antropolojisi Sözlüğü, 171.

20 a.e., 165 .

21 a.e., 266.

22 a.e., 15.

23 Simon Murray ve John Keefe, Physical Theatres, (London: Taylor \& Francis e-Library, 2007), 141.

24 Terzopoulos, Dionysos'un Dönüşü, 16.

25 a.e., 20.

26 Karaboğa, Tragedya ile Sinırları Aşmak, 72. 
“İnsan varlığının özgürleşmemiş bir öteki yanı vardır.... İnsanda ben ve öteki ben birbirinin içine geçmiş durumdadır. Ben 'in başka bir varliğı daha vardır. Bu insan varliğının bölünmü̈şü̆̈̈̈dür. Apollon ve Dionysos arasındaki savaş bu iki benliğin hiç bitmeyen çatışmasını gösterir. Tragedya bu temel çatışmanın enerjisinin ve şiddetinin büyütülmesi anlamına gelir."27

Terzopoulos yukarıda aynı zamanda tragedya ile kurduğu ilişkiyi de açıklamış olur. Tragedyada bulunan bu benlik çatışması, yüksek dozda bulunan enerji ve şiddet hem Antik Yunan Tragedyalarını hem de Heiner Müller gibi çağdaş yazarların oyunlarını sahnelerken Terzopoulos'un araştırmasının temel motiflerini oluşturacaktır. Apollon-Dionysos ayrımı esriyen bedenin çatışmasını barındırır ancak Karaboğa tam bu noktada başka bir benlik ayrımıyla da ilişki kurar ve "şimdiki ben" ve "ilksel ben" arasındaki ayrımdan söz eder:

“Antik Yunan düşüncesi 'şimdiki ben-duygusu'ile 'ilksel ben-duygusu'arasında keskin bir ayrtm çizer. 'Şimdiki ben-duygusu'bir öte dünya ve yeniden doğum tasarımından destek alınarak sıkı bir denetim altında tutulur, bu aynı zamanda Titanlar'dan miras alınan saldırganlık içgüdüsünün bastırılmaya çalışılmasıdır. Diğer taraftan, sadece doğum anında ve ölüm sonrasinda erişilebilen 'ilksel ben-duygusu' yla yaşarken yüzleşmenin yolu ise, her iki boyutun da hakimi olan Dionysos 'a adanmıs törenlerde, Dionisyak esrime anında bulunur."28

Dolayısıyla oyuncu Dionisyak esrime aracılığıyla, oyun anında "şimdiki ben-duygusu"ndan uzaklaşır ve özgürleşmeye başlar. Karaboğa'ya göre bunu gerçekleştirmek için "gizemsel ve ruhaniyetçi telkinlere ihtiyaç yoktur, tam tersine 'tüm organların devindiği bir dans dili'yeterince somut ve fizikseldir. Ve bu fiziksellik sayesinde söz, eylem ve metin de beden tarafindan kuşatılır." En basit haliyle anlatmak gerekirse, fiziksel olarak gündelik hayatta kısıtlanan libidinal enerji bölgesinin çalışmalarda keşfedilmesi ve kullanılması ile "ilksel ben-duygusunun" açığa çıkması sağlanır. Böylece oyuncu geçici ve sınırlı da olsa bir özgürleşme deneyimler, bu "aklşkan ve dinamik bir temas kurmanın sağladığı" bir özgürleşmedir. ${ }^{29}$

Decreus aynı süreci Bilişsel Psikoloji’nin bulgularıyla yorumlarken insan beyninin üç ayrı katmanına değinir. Bunlar beynin sürüngen, eski memeli (limbik) ve yeni memeli (neokorteks) bölümleridir. Her bölümün kendine özgü bir zaman ve uzam algısı vardır. Bu durum, beynimizin üç farklı öznellik ve bilgi formunu taşıdığı anlamına gelir. Kabaca tarif etmek gerekirse beynimizin sürüngen tarafı avlanmayı, doğurmayı, toprak ele geçirmeyi, liderler yaratmayı amaçlarken, limbik beynimiz duygularla meşguldür, neokorteks ise bilinç ve algı ile ilişkili olarak diller ve tanrılar yaratır, ritüeller düzenler. Bu üçü sürekli bir çatışma içindedir ama bir şekilde dönüşerek, birbirini etkileyerek bir arada kalmanın yolunu bulurlar. ${ }^{30}$ Camille

27 Raddatz, Reise mit Dionysos. Das Theater des Theodoros Terzopoulos: Journey with Dionysos. The Theatre of Theodoros Terzopoulos, 152.

28 Karaboğa, Tragedya ile Sinırları Aşmak, 55.

29 a.e., 72.

30 Freddy Decreus, "The Reptilian Brain And The Representation Of The Female In Theodoros Terzopoulos' Bacchai”, Logeion A Journal of Ancient Theatre, Rion/Patras: University of Patras, 2012), 297 ve 298. 
Paglia, neokorteks ile eski limbik ve sürüngen beyinlerimiz arasındaki çatışmanın Apollon ve Dionysos arasındaki çatışmanın kendisi olduğundan bahseder. ${ }^{31}$ Norman Austin de benzer şekilde mitlerdeki çatışmaların beynimizdeki çatışmayı doğrudan yansıttığını söyler. Mitler birbiriyle çatışan algılama ve davranış kalıplarına sahip bu üç yapının uyum sağlama deneyleri gibidir. Neokorteks sürüngen beyni sürekli baskılamaya çalışır, dürtünün yerine iradeyi koymak ister, içgüdünün yerine düşünüp taşınmayı, duyumların yerine tartımı vb. ${ }^{32}$ Savvas Stroumpos bu görüşlerle paralel bir şekilde Terzopoulos’un eğitiminden söz ederken benzer kavramları kullanır: “Oyuncular artık, doğrudan beyinlerindeki korteksten kaynaklanan gündelik hayatın zayıf duygularının kölesi değildir. Aksine, trajik materyalin bedenselleşmesinin ve kodlanmasının temeli sayılan bedenin yaşam enerjisini özgürleştirmenin peşine düşerler." ${ }^{33}$

Terzopoulos'un çalışmaları da insan varoluşunun bu bedensel çatışmalarını ve aynı zamanda bir aradalığını kabul ederek, bütünün oluşturduğu yaşam enerjisinin peşine düşer. Bu enerjinin ortaya çıkması ve bütün bedenin içinde akışkan bir şekilde gezinebilmesi için bedeni önce parçalara ayırır; çalışmak için yedi bölge belirler. Bunlar sırasıyla kuyruk sokumu, üreme organları, aşağı diyafram (aşağı karın), yukarı diyafram, gögüs kafesi, yüz ve beyin korteksidir. Kuyruk sokumu, üreme organları ve aşağı diyafram bir üçgen oluşturur. Diyaframdan nefes alıp verme egzersizleri ile bu bölgenin serbest bırakılması Terzopoulos için ayrı bir öneme sahiptir çünkü bütün bedenin dengesi bu kısımdaki dengeye bağlıdır. Bu bölgenin rahatlığı ayrıca hayvani enerjinin serbest bırakılmasıyla doğrudan ilişkilidir. Kuyruk sokumunun farkına varılması ve aktivasyonu yer çekimi ile ilişkiyi kolaylaştırır. Üreme organlarına ilişkin farkındalık ise bir yandan enerjin akışı doğururken bir yandan da "erkek ya da kadın cinsiyeti ile ilgili kısıtlamalar ve bunlardan kaynaklanan suç ve korkuların yavaş yavaş ortadan kalkmasını" sağlar. Yine aynı şekilde nefes yolu ile aşağı diyafram bölgesi de serbest bırakılmaya çalışılır. Bu bölge "çekim merkezinin desteklenmesi sürecinde anahtar görevi görür" ve güçlenmesi oyuncuya ayrıca özgüven ve kararlılık kazandırır. Zor duruşların üstesinden gelmesini sağlayan da bu bölgenin aktif olmasıdır. ${ }^{34}$

Pelvis bölgesinin oluşturduğu bu üçgenin üstünde, omurga boyunca ilerlediğimizde yukarı diyafram bölgesine ulaşırız. Bu alan nefesin hareket ettiği bir koridor niteliğindedir. Oyuncunun bu alana dair bir his kazanması ve bu bölgeyi rahatlatıp kuvvetlendirilmesi önemlidir çünkü enerji akışı için koridorun açık tutulması ve kaslarının da aktif halde olması gerekir. Bunun üzerinde bulunan 5. bölge göğüs kafesidir. Bu bölgenin rahatlatılması, öncelikle yanlış kullanımı önlemek adına gereklidir. Nefes alırken diyaframını kullanmayan oyuncular sadece bu bölgeye nefes alır ve bu yüzden bu bölge baskın ifade aracı haline gelmiştir. Rahatlatılması enerjinin

31 Camille Paglia, Sexual Personae:Art and Decadence from Nefertiti to Emily Dickinson, (New York: Yale University Press, 1990), 72-98.

32 Norman Austin, Meaning and Being in Myth, (Pennsylvania \& London: Penn State University Press, 1990$), 103$.

33 Savvas Stroumpos, "An Approach to the Working Method of the Attis Teatre", Reise mit Dionysos. Das Theater des Theodoros Terzopoulos: Journey with Dionysos. The Theatre of Theodoros Terzopoulos, Ed. Frank M Raddatz, (Berlin:Theater der Zeit, 2006), 231.

34 Terzopoulos, Dionysos'un Dönüşü, 23-27. 
aşağıdaki üçgene inmesini sağlar. Öte yandan Terzopoulos duygusal baskının ortaya çıkarılması için gögüs kafesine çok fazla yük bindiğinden söz eder. Aynı şekilde gündelik stres ve sinirsel enerji de bu bölgede birikir. Bu yükler duygunun doğal gelişimini engeller. Dolayısıyla bu bölgenin gevşetilmesi nefesin bedenin aşağısına ulaşmasını kolaylaştırırken bir yandan da duygunun doğal yaratımının önünü açar. ${ }^{35}$

Bir diğer bölge olan yüz üzerine çalışmak da aynı şekilde gündelik gerginliğin rahatlatılması ve her türlü ifadeye açık olmayı destekleyecek bir araştırmayı kapsar. Diyafram ve üçgenin açığa çıkardığı enerji ile solunum sırasında dışarı verilen hava yüz kaslarını genleştirir ve çalıştırır. Terzopoulos'un sözünü ettiği son bölge ise beyin korteksidir ve burası bir yandan bilgi barındıran bir alan iken bir yandan da kullanışsızdır çünkü beden ve zihin arasındaki ayrımı destekleyen suç ve korku kaynaklı bilgileri de taşır. Terzopoulos'a göre beyin korteksi "fiziksel dürtülerin doğmasının, hislerin, içgüdülerin ve hayal gücünün serbest bıraklmasının önüne sürekli set çeker." Dolayısıyla oyuncu temel olarak zihin ve beden bütünlüğü üzerine çalışmalıdır. Bu araştırma için Terzopoulos, zihin ve bedenin dinamik bir bütünlük oluşturduğu konsantrasyon ve nefes kontrolü teknikleri önerir. Bu teknikler aracılığıyla, zihnin engelleyici bir denetim mekanizması olmaktan çıkması ve oyuncunun fiziksel hakimiyetini artıran bir dosta dönüşmesi amaçlanır. Terzopolos'a göre zihin ve beden işbirliği doğrudan oyuncunun mevcudiyeti ile ilişkilidir, sözü edilen teknikler onun "her bir anda mutlak bir şekilde var olmasını" kolaylaştırır. ${ }^{36}$

Bütün bu bölgelerin ayrıntılı olarak çalıştırılması her yöne kolaylıkla akabilen enerji dolaşımını sağlamak içindir. Böyle bir akış içerisinde "beden dışarıdan çok sakin görünürken, iç hızı son derece yüksek olacaktır. Bunun koreografi ile hiçbir ilgisi yoktur, koreografinin de bu enerji ile bir ilgisi olmaz. Bu merkezlerle çalışmaktan farklıdır.” Bazı dans ve oyunculuk çalışmalarında karşımıza çıkan ve enerji merkezlerini temel alan araştırmalardan farklı olarak Terzopoulos'un ulaşmaya çalıştığı şey bedenin her bir yerinin merkez olabileceği bir enerji akışıdır. Enerji merkezleri sürekli değişsebilir. Bedenin her bir noktası örneğin deri ya da eller ya da baş her an bir merkeze dönüşebilir. ${ }^{37}$ Esrik bedenin ulaştığı bu akışkanlık ve muğlaklık hali "anlamsızlı̆̆a sürüklenmiş bir soyutlama" hissi olarak algılanmamalıdır. Aynı şekilde mekanik de değildir, Karaboğa onu daha çok "sonradan edinilmiş tüm alışkanlıklarını bir tarafa bırakmış ve önyargısız, en savunmasız haliyle ortaya konmuş bir ilkel bedene" benzetir. ${ }^{38}$

Terzopoulos ilkel beden arayışını modern dünyanın beden anlayışını eleştirerek açıklar. Modern dünyada beden feshedilmiştir; sadece kapitalizme hizmet etmek için vardır. Günümüz insanı "yapayalnız ve tek boyutlu bir bilgisayar haline gelmiş, dönüşüm kabiliyetlerinden

35 a.e., $28-31$.

36 a.e., 32-35.

37 Raddatz, Reise mit Dionysos. Das Theater des Theodoros Terzopoulos: Journey with Dionysos. The Theatre of Theodoros Terzopoulos, 165.

38 Karaboğa, Tragedya ile Sinırları Aşmak, 105. 
yoksun bir obje durumuna" dönüşmüştür. Bu problem yaygın oyunculuk anlayışına da yansır. Çağımızda oyuncu bedeni yalnızca duygulanımların çıktığı bir yer olarak kabul edilir. Bu durumda oyuncu bir süre sonra kendi yaşam öyküsünden medet ummaya başlar. ${ }^{39}$ Oysa Antik kültürde oyuncunun tanımı bedendir. Oyuncu "Beden fikriyle özdeştir... Bugünün tiyatrosu evrensel beden fikrini yeni baştan düşünmeye ve bu düşünceyi kendine özgü bir mizaçla yoğura yoğura ona itibarını geri kazandırmaya mecburdur." ${ }^{40} \mathrm{Bu}$ nedenle Terzopoulos'un bütün çalışmalarının odağında beden vardır. Kendisi de tekniğinin yalnızca bir beden tekniği olduğundan söz eder. Önemli olan sadece tekniği iyi uygulamaktır ve sonrasında “durumun isısı artar. Öyle bir an gelir ki bedende bir şeyler olmaya başlar." ${ }^{41} \mathrm{Bu}$ olan şey doğrudan zihin ve duygularla da ilişkilidir. Dolayısıyla esrime halini oyuncu, bedeni, ruhu ve zihni ile bir bütün olarak deneyimler. Terzopoulos bu deneyimi “kişiye bambaşka bir şekilde hasıl olan özerk bir halet-i ruhiye" 42 olarak tanımlar. Bu her oyuncuya göre değişen, bir bütünsel hal, bir oluştur. Bir şeyi göstermek ya da oynamaktan çok, o anda olma halinin ve deneyimin kendisidir. Terzopoulos bununla mevcudiyeti amaçladığından söz eder; amacı karakter, rol ve psikoloji gibi şeylerin ötesinde "ontolojik açıdan tiyatro öncesi” bir yerdir. ${ }^{43}$ Bir var oluş hali ve biçimidir diyebiliriz.

Terzopoulos için tragedyalar ayrıca bu nedenle de önemlidir, çünkü tragedyalarda karakterler birer varoluş arketipleridir. Karaboğa tragedyanın ontolojik yorumu ile karakterlerini ilişkilendirirken “karakterin gündelik bir 'Ben' ya da kişilikten ayr bir boyutta” olduğundan söz eder. "Tragedyada analiz edilen bir kişilik değil, 'Ben olmayan'la ilişkilendirilebilecek biyolojik dürtüler ile mitleştirilmiş varoluş arketipleridir.” Bu bakış açısını temel alarak, bütün karakterler "gündelik kimliklerinden soyutlanıp birer arketip gibi ele alınabilir". ${ }^{44}$ Oyuncunun rol ve metnin anlamının arkasındaki bu alana girebilmesi psikolojik ve entelektüel bir çözümlemeyle gerçekleşemez. Terzopoulos oyuncunun role ilişkin malzemelerle yüzleşerek, öz farkındalığını geliştirmesi ve içsel dünyasını hareketlendirmesi gerektiğini kabul eder ancak oyuncu arketip olanı daha çok ilkel bedene dönerek keşfedecek ve deneyimleyecektir.

Ritüeller ben bilincinin yok olduğu bir mevcudiyet ve saf bilinç halini içerirler. Geliştirdiği egzersizlerde antik tedavi tekniklerinden ve ilkel büyü törenlerindeki dans ve hareketlerden esinlenmesi bu arketip olana ulaşma araştırması ile ilişkilidir. Karaboğa Terzopoulos'un çalışmalarındaki esrimeler boyunca "oyuncunun 'Ben' bilincinin ve sahne üzerindeki 'Ben' halinin tümden değişim geçirmesinin kaçınılmazlığından” bahseder. Oyuncunun bilinçli kontrolü zayıflar ve esrime durumuna erişir, böylece benliği gündelik algıdan sıyrılarak dönüşüm geçirir. ${ }^{45}$

39 Terzopoulos, Dionysos'un Dönüşü, 70-71.

40 a.e., 71 .

41 Raddatz, Reise mit Dionysos. Das Theater des Theodoros Terzopoulos: Journey with Dionysos. The Theatre of Theodoros Terzopoulos, 161.

42 Terzopoulos, Dionysos'un Dönüşü, 67.

43 Karaboğa, Tragedya ile Sinırları Aşmak, 164.

44 a.e., 133 .

45 a.e., 134. 
Grotowski de aynı şekilde ritüellerden yola çıkarak benzer bir amacın peşine düşmüştür. Bütünsel edim ile ulaşmak istediği şey oyuncunun tümüyle kendini açığa çıkarabildiği bir esrime halidir. Grotowski için bu yüksek benlik hali "bir merkez, bir doruk noktasıdır”. Oysa Terzopoulos için bu hal ulaşllabilir bir şeydir, Hint felsefesinde olduğu gibi, "her zaman ve dinamik bir biçimde diğer bilinç alanlarıla bağlantı halindedir ve yoga, meditasyon gibi teknikler aracılı̆̆ıla beden için ulaşılabilir konumdadır" ${ }^{46}$ Kendi tekniği de bedenin bu hale ulaşmasının yollarından biridir. Teknik olarak nefes ve konsantrasyonun dahil edilmesi ile üçgen ve omurga hissi aktif hale getirilir ve psikosomatik kodlarla enerji akışı sağlanır. ${ }^{47}$

Karaboğa'ya göre oyuncu bu esrime halini deneyimlediğinde, hem ritüelin büyüsünü hatırlatan bir ruh hali hem de uyanık bir sahne duruşu aynı anda belirir. Her ikisi de Terzopoulos'a göre oyuncunun mevcudiyetine anlam katar ve böylece oyuncu

"büyülü bir durumu ifade edebilir. Oyuncunun her kişisel hareketi ezbere öğrenmesi gerekmez; aksine unutmalıdır. Her yeni durum, unutulmuş olanların bir araya toplanmasından başka bir şey değildir. Oyuncu sahnede oynarken her şeyi görmelidir fakat aynı zamanda karşıtını yakalanması da gerekir. Oyuncunun soğukkanlı oynaması gerekirken seyirci tam tersine sicaktır. Bu, oyuncunun seyircinin hislerini kışkırtması gerektiği anlamına gelir ve yine tekniğe dayalıdır." ${ }^{8}$

Terzopoulos burada oyuncunun her yeni ana uyum sağlama becerisinden ve çift bilinçlilikten söz eder. Bunlar da yine teknik aracılığıyla erişilebilir ve gelişebilir durumdadır. Terzopoulos'un sık sık tekniği vurgulaması yönettiği işlerde de kendini gösterir. Bu anlamda sahnede tekniğin görünürlüğünden yanadır. Oyun esnasında oyuncu kullandığı tekniği doğrudan gösterir ve sahneleme biçimi de bu tekniğin ve kurgusallığın altını çizer. Ne seyircinin ne de oyuncunun psikolojik özdeşleşmesine yol açacak hiçbir şey kullanılmaz. Tiyatro hala tiyatrodur, "ama oyuncunun konsantrasyonunun enerji merkezinde olmasının verdiği, yoğun içtenlik ve trajik malzemeyi tüm bedeninde taşıması sayesinde seyirciyi kavrayan bir sahicilik etkisi yaratır." Terzopoulos'a göre bunu yaparken oyuncu aynı zamanda soğukkanlı ve uyanık olmalıdır, aksi takdirde bu etki gerçekleşmez. Oyuncunun "eşzamanlı biçimde hem temsil eder hem de yaşar" durumda olması gerekir. Bu çift bilinçlilik durumu tekniğinin de ön koşuludur. Çünkü oyuncu tekniği uygularken bir yandan dans koreografisi netliğindeki adım, vurgu vb. gibi kuralları yerine getirirken, öte yandan "prova sürecinde olduğu gibi kendi limitlerini en üst seviyede zorlamayı ve bedenindeki akışın kendiliğindenliğine teslim olmayı sürdürür." ${ }^{49}$ Dolayısıla esrimek tümüyle kendinden geçmek ve sahnede olduğunu unutmak anlamına gelmemelidir, tam tersine hem uyanık hem de akışta olmayı gerektiren bir çift bilinçlilik halidir.

46 a.e., 135.

47 Terzopoulos, Dionysos'un Dönüşü, 54.

48 Theodoros Terzopoulos, "Historical Review and Methodology", Theodoros Terzopoulos and The Attis Theatre (History, Methodology and Comments), (Agra Publications, Athens, 2000), s.67 Alıntılayan: Karaboğa, Tragedya ile Sinırları Aşmak, 143-144.

49 Karaboğa, Tragedya ile Sinırları Aşmak, 148. 
Esrime anlarının kendiliğindenliği oyuncuyu bir anlamda belirsizliğin ortasına atar. $\mathrm{Bu}$ belirsizlik Terzopoulos'a göre esrik oyuncuya bir cazibe katar. Burada cazibe kelimesini yaygın anlamıyla kullanmaz. Cazibe oyuncuya ait bir nitelik değildir, doğrudan deneyimin kendisinden kaynaklanan bir çekiciliktir. Cazibeyi esrime deneyiminin bilinmezliği ve her şeye açıklığı üzerine kurulu tedirginlik yaratır. Terzopoulos bunu boşluk ile tarif eder: "Oyuncu boşluğu, kendisini yutma tehlikesine haiz, içinde kaybolup gideceği bir delik olarak görür" ve bu boşlukla ilgili ilkel bir korku duymaya başlar. Boşluk korkutur ve aynı zamanda çeker çünkü "boşlukta açıklanması mümkün olmayan bir sürü şey olur". "Sanki ölüm bir anlı̆̆ına ona kendini gösterir; oyuncu boşluğun yegane zaman dilimi olan ölüm anını tecrübe eder." ${ }^{50}$ Bilinmezlik ve muğlaklık hem korkunun hem de cazibenin kaynağına dönüşür. Bu durum tam da Terzopoulos'un araştırdığ 1 kaotik, her yana yayılabilen enerji biçiminin yaratımını da destekler.

Terzopoulos'un oyunculuk tekniğine dair değinilen tüm bu nitelikler ve beceriler oyuncunun oyun anındaki mevcudiyetini geliştirmek için kullanılabilecek bir çerçeve sunar. Oyuncunun mevcudiyeti kavramı ile beden ve zihnin tüm dikkatinin açık olduğu, oyuncunun tümüyle oyun anında ve orada olduğu yaratım hali kast edilmektedir. Oyunculuk şimdiki zamanda gerçekleşir; o ana dair bir deneyim ve yaratımdır. Oyuncu o anı ve o mekanı konsantrasyonu ile doldurur, ${ }^{51}$ bir anlamda yaratır. Oyuncu böyle anlarda, bu yaratım anının bilinçli farkındalığını deneyimlerken bir yandan da oyunun zaman ve uzam gibi bileşenleri ile bütün bir beden ve zihin olarak ilişkiye girer. Terzopoulos'un çalışmaları da bu anları deneyimlemek ve sürdürmek üzerine derinlemesine araştırmayı içerir. Oyuncunun bütünsel beden algısının gelişimi ve yaşamsal enerjinin dolaşımı için uygulanan fiziksel egzersizler, özellikle yedi bölgenin ayrıntılı çalışılması ve aktifleştirilmesi sayesinde oyuncunun oyunla kurduğu ilişki gelişir. Böylece oyuncunu oyun anındaki mevcudiyeti gelişir. Bütün bu fiziksel uygulamaların en önemli bileşenini nefes oluşturur. Terzopoulos'a göre "soluk alıp vermek bedenin dirimsel işlevidir." Bütün bölgelerin ve enerjinin rahatlatılıp aktifleştirilmesi nefes alış veriş ile ve bunun düzenlenişi ile şekillenir. Karaboğa'nın da belirtiği gibi “Terzopoulos için bedenin metafiziği, onun soluk alıp verme mekanizmasıyla ve bu mekanizmanın ürettiği dinamizmle doğrudan bağlantılıdır." 52 Bütün enerji noktalarına nefesin ulaşması gerekir. Bir odak noktasına yoğunlaşmak ve nefesi oraya yöneltmek ile zihni düşünce gelgitlerinden de kurtarmak mümkündür. Terzopoulos nefes kontrolünün zihni ve gündelik yaşamın düşünce dalgalarını durgunlaştırdığından söz eder. Bu durgunlaşma ile ulaşılan ruhsal "dinginlik çevresel farkındalığl arttırır ve içsel bir mekan ve zaman hissinin kapılarını açar." Zihnin Kartezyen zihin ve beden ayrımındaki görevinden geri çekilmesi ile eşit bir ilişki kurulmaya başlar; zihnin pek çok işlevini beden de özümser ve bütün hücreleri ile düşünür, duyumsar ve hisseder hale gelir. ${ }^{53}$

50 Terzopoulos, Dionysos'un Dönüşü, 66.

51 Anthony Frost ve Ralph Yarrow, Improvisation in Drama, (New York: Palgrave Macmillan, 2007), 113.

52 Karaboğa, Tragedya ile Sinırları Aşmak, 75.

53 Terzopoulos, Dionysos'un Dönüşü, 18-20. 
Nefes bu denge durumunun ateşleyici öğesi gibidir. Hem zihni durgunlaştırmayı sağlarken hem de bedensel enerjiyi aktifleştirir. Bu nedenle Terzopoulos nefesi "esin" kelimesiyle ilişkilendirir. Esinlenmek, "akla tam da nefes kontrolünün önemini getiren, havanın beden içerisindeki serbest dolaşımıyla ilgilidir. Tipkl soluk alıp vermenin (can=soluk) fiziksel deneyiminden ortaya çıkan "ruh" kelimesi gibi." ${ }_{4}$ Phillip Zarilli de, aura ve psyche kelimelerinin eski Yunanca'daki anlamalarında nefes kelimesine rastlar. Yaşamsal enerji, nefesin yaşam veren gücü Sanskritçe "prana” ve Çince "qi”" kelimelerinde de karşımıza çıkar. Bu kelimelerin hepsi hem gerçek anlamıyla alınan nefese hem de yaşamsal bir nitelik olan nefes ve eylemin iç içe geçmesiyle oluşan dolaşım halindeki enerjiye işaret eder. Dolayısıyla enerjinin ortaya çıkışı ve dolaşımı, nefesin de aynı özgür dolaşımı gerçekleştirebilmesiyle mümkün olur. Bu nedenle nefes Terzopoulos'un özellikle üzerinde durduğu yoğun bir çalışma birimidir; günlük egzersizlerin hemen hemen her anında eş zamanlı ve bütünlüklü olarak nefes üzerine çalışılır. Böylece her seferinde nefesin sınırları kendiliğinden biraz daha genişler. Rahatlamış ve açılmış bir nefes bir yandan enerji merkezlerinin özgürleşmesini kolaylaştırırken bir yandan da "beden içerisindeki ses kaynaklarını açı̆̆a çıkarıp vokal becerilerin kapsamını genişletir.” Oyuncu bu sayede farklı tınlatıcıları keşfeder ve bunları doğal yollardan geliştirmenin firsatını bulur. Buradan anlaşılacağı gibi vokal sınırların genişletilmesi ve kullanımı da aynı şekilde bütünlüklü eğitimin bir parçası olarak eş zamanlı ilerler.

Tekniğin içerisinde oyuncu bedeninin uzam ile kurduğu ilişki de benzer şekilde eş zamanlı ve bütünlüklü yürüyen çalışmalarda araştırılır. Terzopoulos'a göre uzam bedendeki dikey ve yatay enerjinin akışı ile oluşur. Somut ve fiziksel mekan Artaud'nun dediği gibi oyuncunun bedeni ile doldurulur. ${ }^{55}$ Böylece, mekan gündelik ve somut olmaktan çıkar ve bedenin enerjisine göre genişleyip daralan ve bu enerji sayesinde görülür olan soyut bir uzama dönüşür. Terzopoulos oyunlarının tasarımında da bu uzam anlayışını sürdürür. Sahne tasarımlarının çoğunda geometrik şekiller, yatay ve dikey çizgilerle oluşturulan soyut mekan tasarımları karşımıza çıkar. Georgios Sampakatakakis, Terzopoulos'un tercihlerinin Bauhaus'un felsefesinden etkilendiğini söyler. $\mathrm{Bu}$ anlamda insan hem duygu hem de akıldır, hem et ve kandan oluşur hem de işlevsel bir makinadır. Mekan da tüm yalınlığı ve matematiksel tasarımı ile bomboş durur ta ki oyuncuların bedeni onu doldurup kolektif bir uzam duyumu yaratana kadar. ${ }^{56}$ Oyuncular çoğunlukla oyunun başından sonuna kadar sahnededir ve sanki "bu alana bilinçli bir biçimde hapsedilmiş gibidirler". Geometrik şekillerin, yani çemberlerin ya da köşegenlerin alanına girdikten sonra oyuncunun oyunu sürdürmekten başka çaresi kalmaz ve Karaboğa'nın ifadesiyle "kendi pathos'unun üzerine yürüyen" trajik kahramanın yazgısını yaşar. ${ }^{57}$

54 a.e., 20.

55 Antonin Artaud, "Mise en Scène and Metaphysics", The Routledge Reader in Politics and Performance, Ed: Lizbeth Goodman, Jane De Gay, (New York: Routledge), 2000, 98.

56 Georgios Sampakatakakis, "Dionysos Restitutes- The Bacchae of Terzopoulos", Reise mit Dionysos: Das Theater des Theodoros Terzopoulos, Journey with Dionysos:The Theatre of Theodoros Terzopoulos, Ed. Frank M Raddatz, (Berlin:Theater der Zeit, 2006), 90.

57 Karaboğa, Tragedya ile Sinırları Aşmak, 100. 
Terzopoulos somut mekanı reddettiği gibi çizgisel ve nesnel zaman anlayışının da dışına çıkar. Dikmen Gürün'e göre Terzopoulos oyunlarında zaman oyuncunun eylemleriyle oluşturulan bir akıştır. Bu akış içerisinde bedenin içinde olanlar açığa çıkar ve "kültürel bellek bedenin kendi tarihiyle buluşur". ${ }^{58}$ Terzopoulos zamanı sonsuzluk olarak kabul edip onu geniş hacimli görmekten bahseder. Asıl araştırma bu alışılmadık, yani doğrusal olmayan geniş hacimli zaman algısına bedeni alıştırmaktır. Sonrasında zaman geliştirilebilir bir şeye dönüşür. ${ }^{59} \mathrm{Bu}$ algının gelişebilmesi için oyuncu inatla zamanın yavaş akışı üzerinde çalışmalıdır. Terzopoulos "zaman boş yere yavaş akmaz" diye ifade eder çünkü yavaş akan bir zaman dilimi içerisinde "çeşitli patlama anlarl, ara zaman dilimleri ve enerji yoğunluklarıyla dolu görünmeyen zaman birimleri” ortaya çıkar. "Oyuncunun bedeni zamanı doğurur; zaman anlam, sezgi ve imgelerin taşlyıcısıdır. Zaman bedene ritim verir ve bunu verirken beden beklenmedik sesler çıkarır... Zaman açılır, büyür ve varsıllaşır." ${ }^{00}$ Dolayısıyla tekniğin eğitimlerinde uygulanan beden ve ses egzersizleri oyuncunun çizgisel zaman ve uzam algısından kurtulması için bir çeşit mesafe oluşturur; öznelliğin araştırılmasını içerir. Zaman ve uzam oyuncunun enerjik bedeninin oluşturduğu birimler olarak genişleyip daralır ya da yavaşlayıp hızlanırlar. Böylece, oyuncu ve oyun sırasında onunla birlikte seyirci de öznel zaman ve uzam deneyimini tecrübe etmiş olur.

Terzopoulos'un Biyodinamik olarak adlandırılan oyunculuk tekniğinin en genel haliyle oyuncu bedeninin enerjisi üzerine çalıştığını söyleyebiliriz. Bu ilk anda Richard Schechner'in mevcudiyet üzerine görüşlerini hatırlatır. Schechner Sri Lanka'da bir tören sırasında izlediği "şeytan dansçısı"ndan bahsederek, batılı anlamda hiçbir standardı karşılamayan ancak bütün kalabalığın dikkatini çekmeyi başaran bir mevcudiyetin varlığından söz eder. "Mevcudiyeti, teatral becerilerinde değildi, taşıdı̆̆ enerjideydi: o bir aracıydı, boruydu, enerji kanalıydı ve enerji onun aracılığıyla görünür oluyordu." ${ }^{61} \mathrm{Bu}$ öte yandan Grotowski’nin de peşine düştüğü oyuncunun auratik mevcudiyeti ile de örtüşür. Cormac Power auratik mevcudiyetten bahsederken aslında Terzopoulos'un amacını özetler gibidir. Power'a göre auratik mevcudiyet oyuncunun ruhsal bir aşkınlığı başarmasından çok, seyirciyi görünen şeyi imgesel olarak aşmaya davet etmesiyle gerçekleşebilir. Böylece seyirci rolün ötesini görüp insanın ne demek olduğuna dair daha bireysel bir his izlemiş olur. ${ }^{62}$ Terzopoulos'un oyuncusu aynı şekilde bilincini tümüyle yitirmediği bir esrime halinde, bedeninde yatay ve dikey enerjinin aktığ 1 ilkel beden araştırmasına düşer ve bu beden içerisinde varoluşu ile yüzleşir.

Bu esrik mevcudiyet hali sahneleme açısından düşünüldüğünde net bir anlam ve biçim önerisinde bulunur; Terzopoulos tiyatrosunun sahneleme dilini oluşturur. Bir oyunculuk

58 Terzopoulos, Dionysos'un Dönüşü, 11.

59 a.e., 61.

60 a.e., 59-60.

61 Richard Schechner, Performance Theory, (New York: Routledge, 2003), 231.

62 Cormac Power, Presence in Play, (Amsterdam - New York: Rodopi B.V., 2008), 83. 
araştırması ve eğitimi olan boyutu ise doğrudan oyuncunun oyun anındaki mevcudiyetini geliştirmek üzerinedir. Bu anlamda bedendeki enerji merkezlerinin hem rahatlamasını hem de aktif hale gelmesini sağlayan tüm fiziksel çalışmalar, nefes ve konsantrasyon araştırmaları, Terzopoulos tiyatrosunun oyuncusu olmasa dahi her oyuncunun sahne mevcudiyetini geliştirmek için başvurabileceği bütünlüklü bir çalışma alanı sunar. Eğitimin bütünlüklü yapısı oyuncunun mevcudiyetini çalışmak için de yapısal bir öneri de bulunur. Nefes, konsantrasyon, his, ses, ritim, zaman ve uzam başından itibaren fiziksel çalışmalar bütününün bir parçasıdır. $\mathrm{Bu}$ bütünlüklü yapı oyuncunun bütün bir bedenzihin olarak çalışmasını, algılamasını ve tepki vermesini kolaylaştırır. Bu bütünsel algı sayesinde oyuncu oyun anının tüm öğeleri ile ilişkiye geçebilir ve her anın getirdiği değişime, risklere açık ve elverişli hale gelebilir. Terzopoulos'un oyuncusu bu sayede katı oyun kurallarını akıcı bir şekilde uygularken bir yandan da esrimenin kendisine teslim olup enerjinin akışını takip edebilir duruma erişir.

Hakem Değerlendirmesi: Dış bağımsız.

Çıkar Çatışması: Yazar çıkar çatışması bildirmemiştir.

Finansal Destek: Yazar bu çalışma için finansal destek almadığını beyan etmiştir.

Peer-review: Externally peer-reviewed.

Conflict of Interest: The author has no conflict of interest to declare.

Grant Support: The author declared that this study has received no financial support.

\section{KAYNAKÇA / BIBLIOGRAPHY}

Artaud, Antonin. "Mise en Scène and Metaphysics", The Routledge Reader in Politics and Performance. Ed.

Lizbeth Goodman, Jane De Gay, 98-101. New York: Routledge, 2000.

Austin, Norman. Meaning and Being in Myth. Pennsylvania \& London: Penn State University Press, 1990.

Barba, Eugenio ve Savarese, Nicola. Oyuncunun Gizli Sanatı: Tiyatro Antropolojisi Sözlüğüu. çev. Ayşın

Candan, Tarhan Onur, Aslı Seven. İstanbul: İstanbul Bilgi Üniversitesi Yayınları, 2017.

Decreus, Freddy. “The Reptilian Brain And The Representation Of The Female In Theodoros Terzopoulos'

Bacchai", Logeion A Journal of Ancient Theatre. vol.2, 284-303., Rion/Patras: University of Patras, 2012.

Frost Anthony ve Yarrow, Ralph. Improvisation in Drama. New York: Palgrave Macmillan, 2007.

Karaboğa, Kerem. Tragedya ile Sinırları Aşmak. İstanbul: E Yayınları, 2008.

McDonald, Marianne. "Theodoros Terzopoulos, A Director For the Ages: Theatre of the Body, Mind, and

Memory", Reise mit Dionysos. Das Theater des Theodoros Terzopoulos: Journey with Dionysos. The Theatre

of Theodoros Terzopoulos. Ed. Frank M Raddatz, 8-41, Berlin: Theater der Zeit, 2006.

Murray, Simon ve Keefe, John. Physical Theatres. Taylor \& Francis e-Library, 2007.

Nişanyan, Sevan. Sözlerin Soy Ağacı: Çağdaş Türkçe’nin Etimolojik Sözlüğü. İstanbul: Adam Yayıncllık, 2003.

Paglia, Camille. Sexual Personae:Art and Decadence from Nefertiti to Emily Dickinson. New York: Yale

University Press, 1990. 
Power, Cormac. Presence in Play. Amsterdam - New York: Rodopi B.V., 2008.

Raddatz, Frank M. “The Metaphysiscs of the Body- Theodoros Terzopoulos in Conversation with Frank M. Raddatz". Reise mit Dionysos. Das Theater des Theodoros Terzopoulos: Journey with Dionysos. The Theatre of Theodoros Terzopoulos, Ed. Frank M Raddatz, 136-175, Berlin: Theater der Zeit, 2006.

Sampakatakakis, Georgios. "Dionysos Restitutes- The Bacchae of Terzopoulos”, Reise mit Dionysos: Das Theater des Theodoros Terzopoulos, Journey with Dionysos:The Theatre of Theodoros Terzopoulos. Ed. Frank M Raddatz, 90-102, Berlin: Theater der Zeit, 2006.

Schechner, Richard. Performance Theory. New York: Routledge, 2003.

Stroumpos, Savvas. "An Approach to the Working Method of the Attis Teatre", Reise mit Dionysos. Das Theater des Theodoros Terzopoulos: Journey with Dionysos. The Theatre of Theodoros Terzopoulos. Ed. Frank M Raddatz, 230-233, Berlin: Theater der Zeit, 2006.

Terzopoulos, Theodoros. Dionysos'un Dönüşü. çev. Burç İdem Dinçel. İstanbul: Habitus Kitap, 2016. 
